\title{
Decomposing the Impact of Credit Card Promotions on Consumer Behavior and Merchant Performance
}

\author{
Dan Geng and Robert J. Kauffman \\ Living Analytics Research Centre, School of Information Systems, Singapore Management University \\ dan.geng.2012@phdis.smu.edu.sg; rkauffman@smu.edu.sg
}

\begin{abstract}
Card-based partnerships between banks and retailers have created new opportunities for profit enhancement. We use public data, together with proprietary data from a financial institution to examine the impact of card-based promotions on consumer behavior and merchant performance. The results show that card promotions are associated with increasing customer traffic and transactions from the bank for its merchant partners. We also found significant variation among offer sizes, types, as well as merchant and consumer segments. Our research creates valuable insights and paves the way forward for decision support.
\end{abstract}

\section{Introduction}

Card products are getting ever more sophisticated and have a mix of hard and soft benefits, including rewards and cash rebates from co-branded loyalty programs, and long-term promotions with retail merchants. Well-designed card programs enable banks to grow targeted customer bases, achieve more merchant purchases and revenues, improve customer benefits and brand awareness [2], and result in a winwin-win outcome [12].

Banks also face fierce competition. Some issuers have learned through failures that an inefficient program may not succeed even after its costs have been reduced [5]. Hence, banks must figure out whether the bundled benefits with a credit card can drive increasing revenue from the merchant partner based on leveraging consumer preferences in a way that creates customer centricity.

Research on card programs in financial services, and loyalty programs, coupons and price promotions in other industries has grown, showcasing perspectives of academic strategists and data analytics specialists. Our work contributes by combining anonymized customer transaction data with public data to investigate the impact of card-based promotions on consumer behavior and merchant performance.

We answer these questions: (1) What are the effects of card-based promotions on merchant sales and consumer purchases through credit cards? (2) Do these promotions drive more customer traffic and transactions with merchant partners from bank cus- tomers? (3) How do the effects vary for promotion size and type, across merchant and customer segments?

We focus on the market of an Asian country and study a popular and transparent business sector, which enabled us to collect merchant data from an online aggregator. We acquired other data, such as credit card offers from the websites of various banks, and anonymized data on transactions and customers from a financial institution. By consolidating the data with a fuzzy matching algorithm, we were able to construct a panel dataset for model estimation.

Our results show positive impacts of card promotions on customer traffic and transaction volume. However, the influence on merchant sales is unclear. We also found varied effects of card promotions among offer sizes and types, as well as for different merchant and customer segments. Our work offers new knowledge about credit card programs and paves the way forward for decision support in banks to more deeply probe credit card customer rewards and loyalty program behavior.

\section{Related Literature}

We will discuss prior studies on credit card rewards, loyalty programs, and price promotions in Finance, Marketing and Information Systems (IS).

\subsection{Card Rewards in Financial Services}

Research related to credit card rewards has investigated a variety of issues, including biased consumer preferences, redemption behavior, and customer loyalty $[7,9,11,13]$. Studies relevant to this research have looked into the impacts of card programs on consumer buying behavior.

Wirtz et al. [21] examined the impact of card loyalty programs on wallet share and suggested that attractive reward programs are likely to increase credit card usage. Ching and Hayashi [6] found through unique empirical research that consumers were willing to switch to cash and checks for in-store payments if card rewards were removed. However, few past works have systematically quantified the effects of such programs. 


\subsection{Loyalty Programs in Other Industries}

Loyalty program studies have been conducted in other contexts such as airlines, hotels, and supermarkets. It is widely accepted in Marketing literature that loyalty programs are profitable for firms $[1,7,15]$. An example is Kopalle et al. [10], who used data from a major hotel chain and found that the reward frequency and customer-tier components of a loyalty program contribute to incremental sales. In the same context, Wang et al. [20] launched a large-scale field experiment and identified increased consumer buying behavior due to loyalty promotions.

Some research suggests otherwise: that loyalty programs are not always producing. Gupta and Lehmann [8] demonstrated that a number of companies invest large amounts of money in loyalty management but receive few tangible profits. Villenueva et al. [19] argued that increased price competition may cause lower profits when firms focus on long-term profit maximization in loyalty programs.

\subsection{Price Discounts and Promotion Types}

There are numerous empirical studies on coupons, price discounts, and other promotion types, that have explored the market responses and dynamics of different promotion sizes and types, and optimal competing strategies for retailers. Neslin [14] estimated a market response model using retailer scanner data and revealed the effects of couponing on market shares. Subramanian and Rao [18] developed a theoretical model, which shows that displaying sales on websites can transform the cannibalization of merchant revenues into an advantage and improve customer acquisition. In contrast, Simonson et al. [17] and Anderson [3] both suggested that sales promotions sometimes serve as adverse signals of product quality, resulting in negative impacts on consumerbuying decisions.

Loyalty programs in financial services, especially credit card programs, differ from those in other industries though. First, typical loyalty programs in retailing are created for a single company, but card promotions often involve multiple stakeholders in the same market. Second, unlike firms in the hospitality, air travel and retailing areas, banks usually have larger and more long-lived customer bases that exhibit higher variation in their preferences. Third, credit card programs offer several types of promotions, including rewards, cash rebates, and price discounts simultaneously. So the research gap in promotionrelated research between financial services and other industries encourages our exploratory work supported by unique data.

\section{Data Description and Research Context}

Our research site involves the credit card market in an Asian country, with a focus on one of the most active and vibrant competitive sectors in the country. We next explain how we built a dataset for empirical analysis by consolidating data from multiple sources and applying machine-based data analytics prior to our implementation of explanatory econometrics.

\subsection{Credit Card Offers from Banks}

By collecting credit card offers from webpages of 4 leading banks (I, II, III and IV), we acquired observations from September to December 2015, including the merchant partner names and offer descriptions. Summary statistics for card offers are in Fig. 1.

\section{Fig. 1. Credit card offers of the 4 banks}

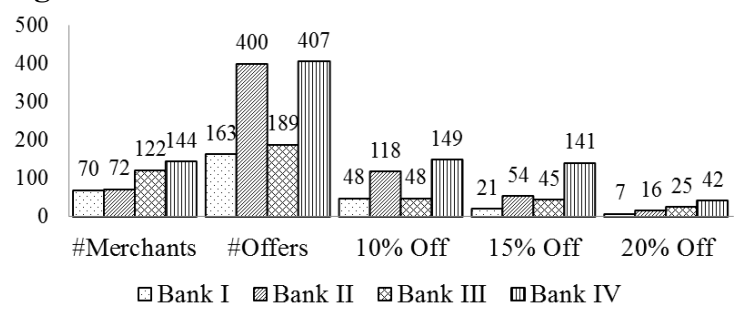

The banks enrolled many merchant partners each: I (70), II (72), III (122) and IV (144). They arranged many deals for the various outlets of the merchants, leading to numerous card-based offers: I (163), II (400), III (189), and IV (407). Most merchants gave a $10 \%$ discount, while others offered $15 \%$ to $20 \%$. Other deals included: one-paid-one-free, special instant rebates, and complementary goods.

\subsection{Merchants in the Local Market}

We collected merchant data from a popular online aggregator with a special focus on the business sector that we investigated. It covers $100,000+$ merchants, from which we obtained review data on 9,811 of the most popular ones. Useful attributes include merchant name, zipcode location, perceived quality score, number of votes, price levels, service type, and other information about the merchants' operations.

Fig. 2. Distribution of merchant quality levels

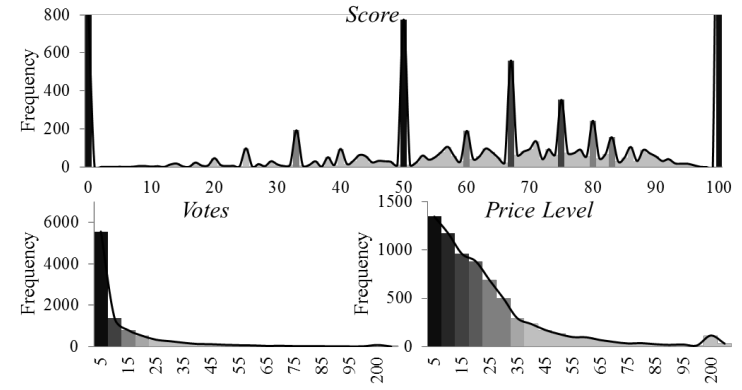


As shown in Fig. 2, the average review scores, votes and prices were $69.58,11.73$ and $\$ 23.44$. The scores tended to be anchored, and the votes and prices had a right-skewed distribution.

To measure consumer purchasing behavior, we acquire anonymized transaction and customer data from a financial institution. Typical transaction information and descriptors were related to customer standing with the bank. Demographic data were also leveraged.

\subsection{Fuzzy Matching to Build the Dataset}

We used a fuzzy matching algorithm based on merchant name, address, phone number and zipcode to connect the multiple datasets. This way, we created a unique dataset, which supports data analytics for deeper insights on the business strategies for banks in card partnerships. Table 1 suggests that banks generally partnered with popular merchants that created customer satisfaction. Bank I preferred the pricier merchants to attract affluent customers, while the other banks targeted lower-priced merchants.

Table 1. Merchant partner averages for 4 banks

\begin{tabular}{|l|c|c|c|c|c|c|c|c|}
\hline \multicolumn{3}{|c}{ BANK I } & \multicolumn{2}{c|}{ BANK II } & \multicolumn{2}{c|}{ BANK III } & \multicolumn{2}{c|}{ BANK IV } \\
\hline & Med. & Mean & Med. & Mean & Med. & Mean & Med. & Mean \\
\hline Score & 72.0 & 69.8 & 60.5 & 54.0 & 67.0 & 63.24 & 72.5 & 69.4 \\
\hline Votes & 15.0 & 26.2 & 11.0 & 17.3 & 14.0 & 27.9 & 13.5 & 24.2 \\
\hline Price & 50.0 & 61.6 & 23.5 & 28.0 & 30.0 & 36.5 & 31.0 & 39.3 \\
\hline
\end{tabular}

Finally, the dataset we used for econometric analysis came to consist of 4,500+ merchants and $400,000+$ customers from September to December 2015. See Table 2.

Table 2. Summary statistics

\begin{tabular}{|c|c|c|c|c|c|}
\hline VARIABLES & \# OBS & MEAN & SE & MIN & MAX \\
\hline Sales & 15,860 & 12,852 & $41,304.52$ & 0 & $1,296,929$ \\
\hline Cust & 15,860 & 149.74 & 880.87 & 0 & 34,244 \\
\hline Trans & 15,860 & 189.93 & $1,466.07$ & 0 & 58,636 \\
\hline MerchTenure & 15,860 & 17.34 & 8.93 & 0 & 27.30 \\
\hline Score & 7,677 & 48.24 & 14.90 & 0 & 70 \\
\hline Votes & 7,677 & 14.90 & 18.12 & 0.7 & 194 \\
\hline Price & 7,152 & 25.05 & 24.79 & 1.4 & 366.80 \\
\hline Store & 8,946 & 1.85 & 4.83 & 0.7 & 90.30 \\
\hline Age & $5,068,316$ & 28.38 & 7.57 & 12.6 & 62.30 \\
\hline Income & $5,068,316$ & $143,267.94$ & $2,331,664$ & 84.0 & $62,222,219$ \\
\hline Children & $5,068,316$ & 0.01 & 0.15 & 0 & 2.80 \\
\hline CustTenure & $5,068,316$ & 85.20 & 59.50 & 0 & 496.30 \\
\hline $\begin{array}{l}\text { Notes. Merchant (Sales, Cust, Trans, MerchTenure) and customer data } \\
\text { (Age, Income, Children, CustTenure) disguised with a multiplier, to } \\
\text { protect the financial institution's identity. }\end{array}$
\end{tabular}

\section{Model and Methodology}

Our access to merchant and customer data allowed estimation of two baseline models, which we will discuss next.

\subsection{Merchant-Level Model}

The merchant-level (j) model is:

$$
\begin{aligned}
\ln \left(\text { Sales }_{j t}\right)= & \beta_{0}+\beta_{1} \text { PartnerBk }_{j t}+\beta_{2} \text { PartnerComp }_{j t} \\
& +\beta_{3} \text { PartnerBk }_{j t} \times \text { PartnerComp }_{j t} \\
& +\beta_{4} \ln \left(\text { Score }_{j}\right)+\beta_{5} \text { ln }\left(\text { Votes }_{j}\right)+\beta_{6} \ln \left(\text { Price }_{j}\right) \\
& +\beta_{7} \text { Stores }_{j}+\beta_{8} \text { MerchTenure }_{j t}+\boldsymbol{\alpha} \text { Service }_{j} \\
& +\gamma \text { Mech }_{j}+\boldsymbol{\sigma} \text { Zip }_{j}+\boldsymbol{\delta} \text { Time }_{t}+\varepsilon_{j t}
\end{aligned}
$$

Here, $\ln \left(\right.$ Sales $\left._{j t}\right)$, is the natural $\log$ of the sales of merchant $j$ at month $t$. We also used the number of customers $\left(\right.$ Cust $\left._{j t}\right)$ and transactions $\left(\right.$ Trans $\left._{j t}\right)$ as alternate measures. Market percentages (\%Sales ${ }_{j t}, \% \mathrm{Cus}$ $t_{j t}, \% \operatorname{Trans}_{j t}$ ) are used for robustness checks.

PartnerBk $k_{j t}$ is binary, to indicate if merchant $j$ had a card partnership with the bank at month $t$. To control for competing effects, merchant partnerships with rival banks (PartnerComp $p_{j t}$ ) were included, along with an interaction term to examine competitor credit card offer effectiveness. We used variables with merchant information, and controlled for 3-digit zip code-level variation in merchant locations $\left(Z i p_{j}\right)$ and time trends $\left(\right.$ Time $\left._{t}\right)$ too. $\varepsilon_{j t}$ is an error term.

\subsection{Customer-Level Model}

We further developed a customer-level model that controls for individual differences, and examines the probability of a consumer $i$ purchasing from a specific merchant using logistic regression:

$$
\begin{aligned}
\operatorname{Pr}_{\left(\text {Purchase }_{i j t}\right)} & =\beta_{0}+\beta_{1} \text { PartnerB }_{j t}+\beta_{2} \text { PartnerComp }_{j t} \\
+ & \beta_{3} \text { PartnerBk }_{j t} \times \text { PartnerComp }_{j t} \\
& +\beta_{4} \ln \left(\text { Score }_{j}\right)+\beta_{5} \ln \left(\text { Votes }_{j}\right)+\beta_{6} \ln \left(\text { Price }_{j}\right) \\
& +\beta_{7} \text { Stores }_{j}+\beta_{8} \text { CustTenure }_{j t}+\boldsymbol{\alpha} \text { Service }_{j} \\
& +\gamma \text { Mech }_{j}+\boldsymbol{\sigma} \text { Zip }_{j}+\boldsymbol{\phi} X_{i t}+\boldsymbol{\delta} \text { Time }_{t}+\mu_{i j t}
\end{aligned}
$$

Purchase $_{i j t}$ is binary to indicate whether customer $i$ purchased from merchant $j$ in month $t$. The number of transactions ( Trans $_{i j t}$ ) is used to check robustness. Besides merchant-level controls, we included $X_{i t}$, a set of individual variables regarding demographics and banking status. We controlled for customer age $\left(\right.$ Age $\left._{i t}\right)$, gender $\left(\right.$ Gender $\left._{i}\right)$, income $\left(\right.$ Income $\left._{i}\right)$, marital status $\left(\right.$ Marriage $\left._{i}\right)$, education level $\left(E d u c_{i}\right)$, nationality $\left(\right.$ Nationality $_{i}$ ), and number of children (\#Childre$\left.n_{i}\right)$. We also included how long the customer was with the bank (Cust Tenure $_{i}$ ), types of credit cards held (CardType ${ }_{i}$ ), and whether the customer had past purchase experience with the merchant (Experience ${ }_{i}$ ) to control for his standing with the bank.

\subsection{Regression Methods}

We applied negative binomial regression, Poisson regression, quantile regression, beta regression and logistic regression to deal with the different response variables in the two baseline models. 


\section{Main Findings of the Research}

We next present the estimation results of the merchant-level and customer-level models.

\subsection{A Matched Merchant Sample}

We first used the full merchant dataset for model estimation, and the results showed significant and positive market responses to card promotions. ${ }^{1,2}$ There was endogeneity with merchant selection by the bank though. It had a strong preference to partner with merchants that had higher sales, higher price levels and more stores, as noted in our descriptive analysis in Table 4. This may have led to overestimated coefficients in the models.

To address this issue, we matched the merchant partners with non-partners. ${ }^{3}$ Table 4 shows that the gaps for the different variables narrowed after matching. Among the ratios we tried, 1:1 matching gave the best results with the closest numbers for the attributes between the partner and non-partner group. Thus, we re-estimated our baseline merchant level model using the 1-to-1 matched merchant sample. See Table 5. Consistent with the full merchant dataset findings, card promotions attracted $28.02 \%$ more consumers and increased transaction volume by $25.99 \%$. ${ }^{4}$ There was no significant impact on merchant sales after

\footnotetext{
${ }^{1}$ We imputed values for missing data with averages for numeric variables and a "missing" indicator for categorical variables. We also used one sample without imputed values for missing data; and another where only missing values due to "No Review" from the aggregator was imputed.

${ }^{2}$ The coefficients for the output variables are $\beta_{\text {PartnerBk }}=$ 0.592 for $\ln ($ Sales $), \beta_{\text {PartnerBk }}=1.018$ for Cust, and $\beta_{\text {PartnerBk }}$ $=1.001$ for Trans; all with $p<0.01$. The coefficients of PartnerComp were also positive $\left(\beta_{\text {Comp }}=0.217, p<0.05\right.$ for $\ln ($ Sales $) ; \beta_{\text {Comp }}=0.182, p<0.01$ for Cust; $\beta_{\text {Comp }}=$ $0.204, p<0.01$ for Trans), suggesting positive impact of card promotions from competitors. But, negative coefficients for the interaction term $\left(\beta_{\text {Partner } \times \text { Comp }}=-0.553, p<\right.$ 0.10 for $\ln ($ Sales $) ; \beta_{\text {Partner } \times \text { Comp }}=-0.416, \mathrm{p}<0.05$ for Cust; $\beta_{\text {Partner } \times \text { Comp }}=-0.345, \mathrm{p}<0.1$ for Trans) mean that parallel promotions from competitors partially offset the effect on merchant performance with customers from the bank

${ }^{3}$ We used propensity score matching based on average monthly values of: prior year sales, evaluated score, votes, price level, number of stores, and tenure with customers of the bank, together with service type, operating mechanism and location. The logit model is specified as $\operatorname{Pr}\left(\right.$ PartnerBk$_{j}$ $=1)=f\left(\ln \left(\right.\right.$ Sales $\left._{j}\right), \ln \left(\right.$ Score $\left._{j}\right), \ln \left(\right.$ Votes $\left._{j}\right), \ln \left(\right.$ Price $\left._{j}\right)$, Merch Tenure $_{j}$, Service $_{j}$, Mech $_{j}$, Zip $\left._{j}\right)$.

${ }^{4}$ The negative binomial models the log of the expected count as a function of the independent variables. The estimated coefficients are interpreted as changes in log expected counts with a unit change in a variable. The change $\%=\left(e^{\text {coef }}-1\right) \times 100 \%=\left(e^{0.247}-1\right) \times 100 \%=$ $28.02 \%$.
}

adjusting for endogenity though.

Table 4. Results of merchant matching

\begin{tabular}{|c|c|c|c|}
\hline VARIABLES & PARTNERS & $\begin{array}{c}\text { NON- } \\
\text { PARTNERS }\end{array}$ & $\begin{array}{l}\text { MATCHED } \\
\text { NON- } \\
\text { PARTNERS }\end{array}$ \\
\hline Sales & $\begin{array}{c}70,371 \\
(-167,008)\end{array}$ & $\begin{array}{c}16,979 \\
(-41,476)\end{array}$ & $\begin{array}{c}69,465 \\
(-155,816) \\
\end{array}$ \\
\hline Score & $\begin{array}{c}61.73 \\
(20.71) \\
\end{array}$ & $\begin{array}{c}69.19 \\
(22.47) \\
\end{array}$ & $\begin{array}{c}61.68 \\
(21.00) \\
\end{array}$ \\
\hline Votes & $\begin{array}{c}23.52 \\
(22.62)\end{array}$ & $\begin{array}{c}21.25 \\
(26.09)\end{array}$ & $\begin{array}{c}29.66 \\
(32.28)\end{array}$ \\
\hline Price & $\begin{array}{c}50.61 \\
(72.38)\end{array}$ & $\begin{array}{c}34.95 \\
(32.92)\end{array}$ & $\begin{array}{c}50.93 \\
(55.41)\end{array}$ \\
\hline Stores & $\begin{array}{c}10.50 \\
(23.06)\end{array}$ & $\begin{array}{c}2.37 \\
(5.52)\end{array}$ & $\begin{array}{c}9.59 \\
(20.63)\end{array}$ \\
\hline MerchTenure & $\begin{array}{l}21.25 \\
(5.06) \\
\end{array}$ & $\begin{array}{l}18.04 \\
(8.06) \\
\end{array}$ & $\begin{array}{l}21.04 \\
(5.45) \\
\end{array}$ \\
\hline Obs. & 64 & 2,212 & 64 \\
\hline \multicolumn{4}{|c|}{$\begin{array}{l}\text { Notes. Std err. in parens. } 1: 1 \text { matching ratio applied. } 1: 2,1: 5 \text {, and } \\
1: 10 \text { matches used for comparisons. Merchant (Sales, MerchTenure) } \\
\text { disguised with a multiplier, to protect the identity of the financial } \\
\text { institution from being disclosed. }\end{array}$} \\
\hline
\end{tabular}

Table 5. Baseline merchant-level model results with matched merchant sample

\begin{tabular}{|c|c|c|c|}
\hline & $\ln ($ Sales $)$ & Cust & Trans \\
\hline Intercept & $\begin{array}{c}-6.653 * * * \\
(1.719) \\
\end{array}$ & $\begin{array}{c}-5.799 * * * \\
(1.139) \\
\end{array}$ & $\begin{array}{c}-5.828 * * * \\
(1.159) \\
\end{array}$ \\
\hline PartnerBk & $\begin{array}{c}-0.003 \\
(0.187) \\
\end{array}$ & $\begin{array}{l}0.247 * * \\
(0.119) \\
\end{array}$ & $\begin{array}{l}0.231^{*} \\
(0.122) \\
\end{array}$ \\
\hline PartnerComp & $\begin{array}{c}0.462 \\
(0.325) \\
\end{array}$ & $\begin{array}{c}0.077 \\
(0.194) \\
\end{array}$ & $\begin{array}{c}0.059 \\
(0.198) \\
\end{array}$ \\
\hline $\begin{array}{c}\text { PartnerBk } \times \\
\text { PartnerComp }\end{array}$ & $\begin{array}{l}-0.607 \\
(0.387) \\
\end{array}$ & $\begin{array}{l}-0.200 \\
(0.235) \\
\end{array}$ & $\begin{array}{l}-0.173 \\
(0.239) \\
\end{array}$ \\
\hline \multicolumn{4}{|c|}{$\begin{array}{l}\text { Notes. } 508 \text { obs.; std. err. in parens. OLS used for } \ln (\text { Sales }) \text {, neg. bin. } \\
\text { used for Cust and Trans. Poisson model estimated for robustness. } \\
\text { Control var. estimates suppressed. Signif. } *=p<0.10 ; * *=p< \\
0.05 ; * * *=p<0.01 \text {. }\end{array}$} \\
\hline
\end{tabular}

Why? Possibly due to cannibalization of merchant revenues from existing customers, when there are extra price discounts. Thus, the overall impact on sales depended on the tradeoff between the increase in quantities and the reduction in prices. Also, loyalty programs that discriminate against non-loyal customers may lead to their dissatisfaction, and hence switching to competitors [16].

\subsection{Baseline Customer-level Model Results}

The results of the customer-level and merchantlevel model were consistent. As Table 6 shows, card promotions resulted in a $62.8 \%$ increase in the bank's customers' likelihood to purchase. It also increased customer monthly transactions. Similar results regarding parallel promotions from competing banks were acquired for the customer-level model, suggesting card promotions from competing banks offset the overall promotion effects of offers by the bank. 
Table 6. Baseline customer-level model results

\begin{tabular}{|c|c|c|}
\hline \multicolumn{1}{|c|}{ Purchase } & Trans \\
\hline \multirow{2}{*}{ Intercept } & -15.906 & $-25.771^{* * *}$ \\
& $(16.314)$ & $(1.191)$ \\
\hline \multirow{2}{*}{ PartnerBk } & $0.628^{* * *}$ & $0.638^{* * *}$ \\
& $(0.032)$ & $(0.030)$ \\
\hline \multirow{2}{*}{ PartnerComp } & $0.105^{* * *}$ & $0.075^{* * *}$ \\
& $(0.027)$ & $(0.028)$ \\
\hline PartnerBk $\times$ & $-0.266^{* * *}$ & $-0.211^{* * *}$ \\
PartnerComp & $(0.038)$ & $(0.038)$ \\
\hline Notes. 5,068,316 obs.; std. errs. in parens. Logit used for Pur- \\
chase; neg. bin. used for Trans. Poisson model estimated for ro- \\
bustness. Control var. estimates suppressed. Signif. * $=p<0.10 ;$ \\
$* *=p<0.05 ; * * *=p<0.01$. \\
\hline
\end{tabular}

\subsection{Promotion Size Decomposition}

To examine the effects of different sizes and types of promotions, we decomposed the partnership indicator into specific offers, for discounts, cash rebates, rewards and other promotion types (one-paid-onefree, complementary goods, and report in Table 7.

Table 7. Decomposition results for promotion size

\begin{tabular}{|c|c|c|c|c|c|}
\hline & \multicolumn{3}{|c|}{ MERCHANT-LEVEL } & \multicolumn{2}{|c|}{ CUSTOMER-LEVEL } \\
\hline & $\ln ($ Sales $)$ & Cust & Trans & Purchase & Trans \\
\hline Intercept & \begin{tabular}{|c|}
$-7.203 * * *$ \\
$(1.831)$ \\
\end{tabular} & $\begin{array}{l}-1.365 \\
(1.160) \\
\end{array}$ & $\begin{array}{l}-16.333 \\
(16.243)\end{array}$ & $\begin{array}{c}-10.630 * * * \\
(1.050)\end{array}$ & $\begin{array}{l}-110^{*} \\
(1.187)\end{array}$ \\
\hline $\begin{array}{c}\text { PartnerBk: } \\
10 \% \text { Disc }\end{array}$ & \begin{tabular}{|c|}
$-0.696 * * *$ \\
$(0.265)$ \\
\end{tabular} & $\begin{array}{l}-0.193 \\
(1.152) \\
\end{array}$ & \begin{tabular}{|c|}
$-0.439 * * *$ \\
$(0.106)$ \\
\end{tabular} & $\begin{array}{c}-0.313 * * * \\
(0.055) \\
\end{array}$ & $\begin{array}{l}-0.154 \\
(0.156) \\
\end{array}$ \\
\hline $\begin{array}{c}\text { PartnerBk: } \\
15 \% \text { Disc }\end{array}$ & $\begin{array}{c}0.455 \\
(0.437) \\
\end{array}$ & $\begin{array}{c}0.857 * * * \\
(0.291)\end{array}$ & $\begin{array}{l}0.214 * \\
(0.112) \\
\end{array}$ & $\begin{array}{l}0.144 * \\
(0.079) \\
\end{array}$ & $\begin{array}{c}0.740 * * \\
(0.301)\end{array}$ \\
\hline $\begin{array}{c}\text { PartnerBk: } \\
20 \% \text { Disc }\end{array}$ & $\begin{array}{l}-0.112 \\
(0.610) \\
\end{array}$ & $\begin{array}{c}0.176 \\
(0.348) \\
\end{array}$ & \begin{tabular}{|c|}
$0.565 * * *$ \\
$(0.102)$ \\
\end{tabular} & $\begin{array}{c}0.664 * * * \\
(0.055) \\
\end{array}$ & $\begin{array}{c}0.074 \\
(0.358) \\
\end{array}$ \\
\hline $\begin{array}{c}\text { PartnerBk: } \\
\text { Rebate }\end{array}$ & $\begin{array}{c}0.409 \\
(0.385) \\
\end{array}$ & $\begin{array}{c}1.267 * * * \\
(0.250)\end{array}$ & $\begin{array}{c}1.699 * * * \\
(0.101)\end{array}$ & $\begin{array}{c}1.932 * * * \\
(0.046)\end{array}$ & $\begin{array}{c}1.303 * * * \\
(0.258)\end{array}$ \\
\hline $\begin{array}{c}\text { PartnerBk: } \\
\text { Reward }\end{array}$ & $\begin{array}{c}0.128 \\
(0.362) \\
\end{array}$ & $\begin{array}{c}0.102 \\
(0.220) \\
\end{array}$ & $\begin{array}{l}-0.132 \\
(0.100) \\
\end{array}$ & $\begin{array}{l}-0.054 \\
(0.048) \\
\end{array}$ & $\begin{array}{c}0.046 \\
(0.225) \\
\end{array}$ \\
\hline $\begin{array}{c}\text { PartnerBk: } \\
\text { Other }\end{array}$ & $\begin{array}{c}0.648 \\
(0.499) \\
\end{array}$ & $\begin{array}{c}0.426 \\
(0.363) \\
\end{array}$ & $\begin{array}{c}0.948 * * * \\
(0.127) \\
\end{array}$ & $\begin{array}{c}1.005 * * * \\
(0.094)\end{array}$ & $\begin{array}{c}0.393 \\
(0.385) \\
\end{array}$ \\
\hline \multicolumn{6}{|c|}{$\begin{array}{l}\text { Notes. } 508 \text { obs. for merchant model and } 5,068,316 \text { obs. for customer } \\
\text { model; Disc }=\text { merchandise discount. Std. errs. in parens. OLS used } \\
\text { for } \ln (\text { Sales); neg. bin. used for Cust and Trans; logit used for Pur- } \\
\text { chase. Poisson model estimated for robustness. Control estimates } \\
\text { suppressed. Signif. } *=p<0.10 ; * *=p<0.05 ; * * *=p<0.01 \text {. }\end{array}$} \\
\hline
\end{tabular}

In price promotions, a $15 \%$ discount had the strongest impact on merchant sales, customer traffic and transactions $\left(\beta_{\text {PartnerBk }}=0.937, p<0.05\right.$ for $\ln ($ Sales $) ; \beta_{\text {PartnerBk }}=1.067, p<0.01$ for Cust; $\beta_{\text {Part- }}$ ${ }_{n e r B k}=1.037, p<0.01$ for Trans). Lower or higher discounts showed weak or inverse effects. There was more market response to other promotion types, especially cash rebates than price discounts.

\subsection{Sales Stratification}

We stratified $\ln ($ Sales $)$ in the merchant-level model using quantile regression. As shown in Fig. 5, the effects of card promotions were negative in the lower quantiles and became positive between the 60 th to 90 th quantiles. The offset effect of parallel offers from competitors was lower above the 70th quantile, while it was largest between the 20th and 65 th quantiles.

Fig. 5. Quantile regression results

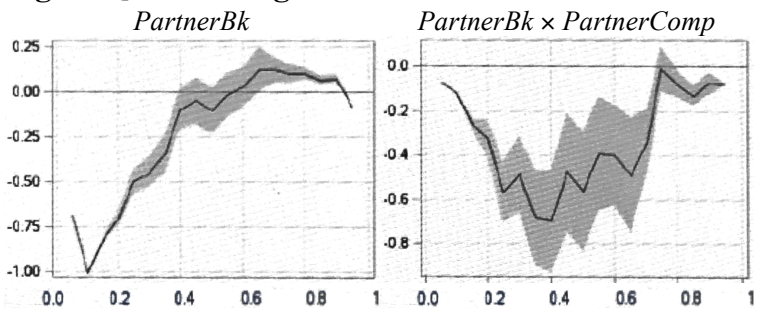

\subsection{Merchant and Customer Segmentation}

We conducted segment subsampling based on the medians of Score, Votes, Price, MechTenure and Stores, and estimated the merchant-level model using the subsamples. In Fig. 6, popular and pricier merchants showed higher profitability and customer attraction capability. The coefficients of Score, MechTenure and Store were negative, though lower scores, higher tenure and stores were better off.

Fig. 6. Merchant and customer segment results

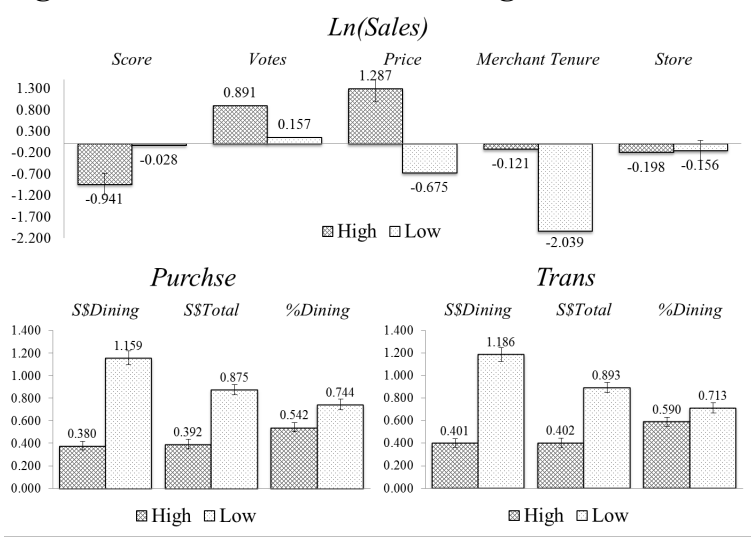

We looked into customer segments based on their average monthly spend in the targeted business sector, in all sectors, as well as the percentage, and show the between-groups results in Fig. 7. The results consistently show that heavy spenders were less likely to react to credit card promotions, while the offers were more attractive to light spenders, probably due to different price sensitivities across customer groups.

\subsection{Robustness Checks}

We turned to shares of Sales, Cust, and Trans and used beta regression for robustness checks. The results in Table 8 are consistent with our earlier analysis, providing additional support for our conclusions. 
Table 8. Robustness estimation results

\begin{tabular}{|c|c|c|c|}
\hline & \multicolumn{3}{|c|}{ RELATIVE MARKET SHARES } \\
\hline & \%Sales & $\%$ Cust & $\%$ Trans \\
\hline Intercept & $\begin{array}{c}-7.857 * * * \\
(0.269) \\
\end{array}$ & $\begin{array}{c}-7.043 * * * \\
(0.292)\end{array}$ & $\begin{array}{c}-7.109 * * * \\
(0.297)\end{array}$ \\
\hline PartnerBk & $\begin{array}{c}0.078 \\
(0.051)\end{array}$ & $\begin{array}{c}0.208 * * * \\
(0.059)\end{array}$ & $\begin{array}{c}0.223 * * * \\
(0.059)\end{array}$ \\
\hline PartnerComp & $\begin{array}{c}0.176 * * \\
(0.071)\end{array}$ & $\begin{array}{l}0.157 * \\
(0.080)\end{array}$ & $\begin{array}{c}0.103 \\
(0.086)\end{array}$ \\
\hline $\begin{array}{l}\text { PartnerBk } \times \\
\text { PartnerComp }\end{array}$ & $\begin{array}{l}-0.167 * \\
(0.088)\end{array}$ & $\begin{array}{l}-0.146 \\
(0.098) \\
\end{array}$ & $\begin{array}{l}-0.093 \\
(0.102) \\
\end{array}$ \\
\hline \multicolumn{4}{|c|}{$\begin{array}{l}\text { Notes. } 508 \text { obs. Std. errs. in parens. Beta regression used for } \\
\% \text { Sales, } \% \text { Cust and } \% \text { Trans; neg. bin. used for Trans; and logit } \\
\text { used for Purchase. Poisson model estimated for robustness. } \\
\text { Control var. estimates suppressed to save space. Signif. }{ }^{*}=p< \\
0.10 ; * *=p<0.05 ; * *=p<0.01 \text {. }\end{array}$} \\
\hline
\end{tabular}

\section{Conclusion}

The proliferation of credit card products and cardbased programs has created opportunities for banks enhance profitability. This research investigated how consumer behavior and merchant performance may be affected by card-based programs. We contributed new knowledge for card marketing between banks and retailers. We also offered useful policy analytics ideas, and supports reconsideration of business policy in the card promotions domain. In addition, we delivered results that pave the way for decision support in banks to more deeply probe credit card customer rewards and loyalty program behavior.

We leveraged machine-based big data techniques to acquire data from public domain and combine it with the proprietary data of a financial institution. In spite of this, we recognize several limitations. First, the merchant data we obtained from the online aggregator was from a single time point. We were unable to capture the changing quality attributes of the merchants in our model. Second, the card promotions drawn from bank websites tend to cover longer-term partnerships with retailers. Ad hoc offers, which were not displayed on the webpages, were not included. Third, techniques such as screen-scraping and database harvesting did not allow us to obtain historical data. Thus, we were unable to conduct "within" comparisons for estimates of higher fidelity. Last, the business sector we focused on is just one among many others in which consumers use credit cards to purchase and acquire benefits. Such efforts offer new and useful insights on customer behavior for firms and organizations in many other sectors.

Acknowledgments. This research was done under a binding non-disclosure agreement with a corporate sponsor, requiring the anonymization of all data that were used and analyzed. No personally-identifiable information about customers has been disclosed or shared. This research was supported by the Singapore
National Research Foundation under the International Research Centre@ Singapore Funding Initiative, administered by the Interactive Digital Media Programme Office (IDMPO). The authors acknowledge the Living Analytics Research Centre at Singapore Management University for logistical support.

\section{References}

[1] Agustin, C., Singh, J. Curvilinear effects of consumer loyalty determinants in relational exchanges. $J$. Mktg. Res, 42(1), 2005, 96-108.

[2] AIMIA. The future of rewards: how rewards will help build real relationships. The Bulletin, Montreal, Canada, 2015.

[3] Anderson, E.T., Simester, S.I. Price discrimination as an adverse signal: why an offer to spread payments may hurt demand. Mktg. Sci., 20(3), 2001, 315-327.

[4] Bolton, R., Kannan, P. Implications of loyalty program membership and service experiences for customer retention and value. J. Acad. Mktg. Sci., 28(1), 2000, 95108, 2000.

[5] Booz \& Co. Spending power: cards strategy series. New York, NY, 2005.

[6] Ching, A., Hayashi, F. Payment card rewards programs and consumer payment choice. J. Bkg. Fin., 34(8), 2010, 1773-1787.

[7] Fornell, C., Johnson, M.D., Anderson, E.W., Cha, J. and Bryant B. Everitt, B.B. The American Customer Satisfaction Index: nature, purpose, and findings. $J$. Mktg., 60(4), 1996, 7-18.

[8] Gupta, S., Lehmann, D.R. Managing Customers as Investments: The Strategic Value of Customers in the Long Run. Wharton School Publ., Upper Saddle River, NJ, 2005.

[9] Keh, H., Lee, Y. Do reward programs build loyalty for services? the moderating effect of satisfaction on type and timing of rewards. J. Ret., 82(2), 2006, 127-136.

[10] Kopalle, P.K., Sun, Y., Neslin, S.A., Sun, B., Swaminathan, V. The joint sales impact of frequency reward and customer tier components of loyalty programs. Mktg. Sci., 31(2), 2012, 216-235.

[11] Liu, M., Brock, J. Redemption behavior for credit card reward programs in China. Intl. J. Bank Mktg., 27(2), 2009, 150-166.

[12] McKinsey \& Co. Creating value through credit card partnerships in Latin America. New York, NY, 2011.

[13] Meier, S., Sprenger, C. Present-biased preferences and credit card borrowing. Amer. Econ. J.: App. Econ. 2(1), 2010, 193-210, 2010.

[14] Neslin, S.A. (1990) A market response model for coupon promotion. Mktg. Sci. 9(2), 1990, 125-145.

[15] Reichheld, F.F., Teal, T. The Loyalty Effect: The Hidden Force Behind Growth, Profits and Lasting Value. Harvard Bus. School Press, 2001, Boston, MA.

[16] Shugan, S.M. Brand loyalty programs: are they shams? Mktg. Sci., 24(2), 2005, 185-193.

[17] Simonson, I., Carmon, Z., O'Curry, S. Experimental 
evidence on the negative effect of product features and sales promotions on brand choice. Mktg. Sci., 13(1), 1994, 23-40

[18] Subramanian, U., Rao, R.C. Leveraging experienced consumers to attract new consumers: equilibrium analysis of displaying deal sales by daily deal websites. Mgmt. Sci., in press.

[19] Villenueva, J., Bharadwaj, P., Balasubramanian, S., Chen, Y. Customer relationship management in competitive environments: the positive implications of a short-term focus. Quant. Mktg. Econ. 5(2), 2007, 99129.

[20] Wang, Y., Lewis, M., Cryder, C., Sprigg, J. Enduring effects of goal achievement and failure within customer loyalty programs: a large-scale field experiment. Mktg Sci., in press.

[21] Wirtz, J., Mattila, A., Lwin, M. How effective are loyalty reward programs in driving share of wallet? $J$. Serv. Res., 9, 2007, 327-334. 